\title{
Sundown Syndrome in Persons with Dementia: An Update
}

\author{
Nina Khachiyants ${ }^{1}$, David Trinkle ${ }^{2,3}$, Sang Joon Son ${ }^{4,5}$ and Kye Y. Kim ${ }^{3,6} \bowtie$ \\ ${ }^{1}$ Carilion-Virginia Tech School of Medicine Geriatric Psychiatry Fellowship Program Roanoke, VA, USA \\ ${ }^{2}$ Carilion Clinic, Roanoke, VA, USA \\ ${ }^{3}$ Department of Psychiatry and Behavioral Sciences Virginia Tech Carilion School of Medicine, Roanoke, VA, USA \\ ${ }^{4}$ Gwangju Community Mental Health Center, Gwangju, Korea \\ ${ }^{5}$ Department of Psychiatry, College of Medicine, Yonsei University, Seoul, Korea \\ ${ }^{6}$ Salem Veterans Affairs Medical Center, Salem, VA, USA
}

\begin{abstract}
"Sundowning" in demented individuals, as distinct clinical phenomena, is still open to debate in terms of clear definition, etiology, operationalized parameters, validity of clinical construct, and interventions. In general, sundown syndrome is characterized by the emergence or increment of neuropsychiatric symptoms such as agitation, confusion, anxiety, and aggressiveness in late afternoon, in the evening, or at night. Sundowning is highly prevalent among individuals with dementia. It is thought to be associated with impaired circadian rhythmicity, environmental and social factors, and impaired cognition. Neurophysiologically, it appears to be mediated by degeneration of the suprachiasmatic nucleus of the hypothalamus and decreased production of melatonin. A variety of treatment options have been found to be helpful to ameliorate the neuropsychiatric symptoms associated with this phenomenon: bright light therapy, melatonin, acetylcholinesterase inhibitors, N-methyl-d-aspartate receptor antagonists, antipsychotics, and behavioral modifications. To decrease the morbidity from this specific condition, improve patient's well being, lessen caregiver burden, and delay institutionalization, further attention needs to be given to development of clinically operational definition of sundown syndrome and investigations on etiology, risk factors, and effective treatment options.

Psychiatry Investig 2011;8:275-287
\end{abstract}

Key Words Sundowning, Alzheimer's disease, Dementia.

\section{INTRODUCTION}

Sundown syndrome, also known as sundowning, is a common clinical phenomenon manifested by the emergence or increment of neuropsychiatric symptoms in the late afternoon, evening or at night. It particularly occurs among cognitively impaired, demented, or institutionalized elderly patients. ${ }^{1,2}$ Sundowning is a descriptive term and not a psychiatric diagnosis formally recognized in the DSM-IV-TR. Despite the lack of a formal recognition, "sundowning" is broadly used to describe a set of neuropsychiatric symptoms occurring in elderly patients with or without dementia at the time of sunset, at evening, or at night. These behaviors represent a wide variety of symptoms such as confusion, disorientation, anxiety, agitation, aggression, pacing, wandering, resistance to redirec-

Received: December 28, 2010 Revised: March 29, 2011

Accepted: April 12, 2011 Available online: November 4, 2011

$\triangle$ Correspondence: Kye Y. Kim, MD

Building 7-1, VA Medical Center, Salem, VA 24018, USA

Tel: +1-540-982-2463, Fax: +1-540-983-1080, E-mail: kye.kim@med.va.gov

(@) This is an Open Access article distributed under the terms of the Creative Commons Attribution Non-Commercial License (http://creativecommons.org/licenses/by$\mathrm{nc} / 3.0$ ) which permits unrestricted non-commercial use, distribution, and reproduction in any medium, provided the original work is properly cited. tion, screaming, yelling and so forth. Some of these behaviors may not be specific to sundowning and can be the manifestation of dementia, delirium, Parkinson's disease, and sleep disturbances.

However, what distinguishes sundowning from above mentioned conditions is that persons with sundown syndrome characteristically show disruptive behaviors specifically in the late afternoon, in the evening, or at night. ${ }^{2}$ They can be very challenging to caregivers to deal with those symptoms. One study indicates that agitation from sundown syndrome is a common cause of institutionalization of older patients suffering from dementia. ${ }^{3}$ Other clinical features of sundowning include mood swings, abnormally demanding attitude, suspiciousness, and visual and auditory hallucinations in the late afternoon and evening. ${ }^{4}$

Geriatric clinicians have frequently observed that some demented individuals show increased agitation, restlessness and confusion in late afternoon, evening or night. This has popularly been named "sundowning" or "sundown syndrome". Clinical observations on sundowning are multiple in medical literatures, but they have failed to arrive at a consensus as to its definition. They also disagree on almost every aspect of the syn- 
drome. ${ }^{5}$ Research data related to this unique clinical phenomenon are limited to date. Cameron described this phenomenon in 1941 as "nocturnal delirium" and "delirium and agitation within one hour of darkness". Prinz and Raskind ${ }^{6}$ defined sundowning as a marked increase in confusion, disorientation and possibly agitation in an elderly or severely cognitively impaired subject at sunset or when daylight is reduced. Other clinical manifestations associated with sundowning are screaming, delusional thinking, moaning and wandering. ${ }^{6}$ Volicer et al. ${ }^{4}$ defined sundowning as "the appearance or exacerbation of behavioral disturbances associated with the afternoon and/or evening hours". Sadock described sundowning as "a syndrome in older persons that usually occurs at night and is characterized by drowsiness, confusion, ataxia, and falling as the result of being overly sedated with medications." According to Bliwise, the term "sundowning" was used in geriatric medicine to describe "the phenomenon of agitation seemingly caused by, or at least strongly associated with darkness". Several researchers have found no clinical correlation between exacerbation of behavioral abnormalities and circadian rhythm, and even question the existence of sundowning. ${ }^{9-12}$ They consider the disruptive behavior in demented patients later during the day to be rather an exacerbation of existing day time behavioral abnormalities and new symptoms occurring primarily in the late afternoon. Also, agitated behavior of institutionalized patients has greater impact on nursing home staff in the evening. ${ }^{9-12}$ Although other investigators demonstrated a great variability in the peak time of behavioral worsening, they all reported the maximal behavioral disruption sometime in the later afternoon or evening.,13

It is difficult to differentiate wide variety of temporal behavioral disruptions in demented patients, and their correlation with other non-circadian rhythm related factors. Nevertheless, there is enough evidence in neurologic and psychiatric literature to suggest existence of a sundowning-type phenomenon in demented or cognitively impaired individuals, which according to literature data includes a constellation of emotional, cognitive, behavioral, and motor dysfunction. . $2,4,5,9,13-20^{2}$

\section{METHODS}

A systematic search of the medical literature published in English between 1940 and 2010 performed using Pub Med, Medline, and other databases and sources. Search terms included: sundowning, sundowning syndrome, sundown syndrome, and dementia. All literature on definition, epidemiology, etiology, risk factors, diagnosis, differential diagnosis, treatment, prognosis, and prevention of sundowning syndrome were retrieved.

\section{RESULTS}

\section{Epidemiology}

Currently, there is sparse literature on epidemiology of sundown syndrome. Data available on prevalence rates for sundown syndrome is variable. It depends on patient population and setting. According to the data from Alzheimer's Association in 2006, 2.4\% to $25 \%$ patients diagnosed with Alzheimer's disease (AD) had sundown syndrome. ${ }^{21}$ Currently, there is no data on prevalence in gender, race and types of dementing disorders. Although the prevalence of sundowning among patients with severe dementia is particularly high, this syndrome appears to affect virtually all patients with some degree of cognitive impairment. ${ }^{1,22}$ Sundowning is considered to be the second most common type of disruptive behavior in institutionalized patients with dementia after wandering. ${ }^{23}$ It appears to be endemic among institutionalized adults with dementia. Evans in her study at a nursing home facility found that $12.4 \%$ of elderly patients from general nursing home population demonstrated significant changes in cognitive status in the late afternoon. ${ }^{13}$ Based on various data, the overall rates of sundowning among patients with $\mathrm{AD}$ or other types of dementia ranges from $2.4 \%$ to $66 \% .^{10,20-25}$ Gallagher-Thompson and associates, reported that the prevalence of sundowning as high as $66 \%$ among patients living at home. ${ }^{26}$ Based on available data, it is impossible to do a valid comparative analysis of prevalence of sundowning syndrome in two different patient populations: institutionalized and non-institutionalized. The severity of cognitive impairment may be one of the important predisposing factors in the development of sundown syndrome. ${ }^{22}$ Volicer at al. ${ }^{4}$ reported that sundowning was also linked to the seasons with increased incidence in the fall or winter months due to a decrease in duration and amount of sunlight.

\section{Etiology}

The exact cause of sundown syndrome is unknown. Several theories have been proposed to understand the clinical phenomenon of sundowning. Studies that have attempted to explain etiology of sundown syndrome can be divided into three major groups: physiological, psychological, and environmental. ${ }^{22}$

\section{Sensory deprivation}

One of the earliest studies on environmental factors and psychophysiological variables in development of "nocturnal delirium" was done by Cameron1 in 1941. Ancoli-Israel et al. ${ }^{27}$ indicated that patients with $\mathrm{AD}$ already have inadequate exposure to amounts of light during the day. This finding formulates the rationale for light therapy in demented patients. Morley ${ }^{28}$ described a person with visual impairment due to macular degeneration, who repeatedly developed classic sun- 
downing syndrome with changes in perception as day shifted into twilight. Among many factors, $S m_{i t h}{ }^{29}$ indicated that low lighting and increased shadows may aggravate late-day confusion and sundowning. Duckett ${ }^{22}$ has suggested significant differences in amount of light in various parts of the hospital that may not be readily apparent to the healthy eye. This suggestion was discussed as the basis for modification of ambient light by "matching light readings attained from the day and evening hours."22

\section{Circadian rhythm disorders}

Majority of recent studies have focused on the important potential role of disordered circadian rhythm as an etiological factor of sundown syndrome in patients with dementia. According to these studies, sundowning as a nonspecific symptom of different types of dementia may be a manifestation of specific path physiologic abnormalities that interfere with normal circadian rhythm and behavioral regulation. ${ }^{4,20,30-34}$ In one study which investigated sundowning phenomenon in terms of disturbance in circadian rhythm or changes in sleepwake cycles, Feinberg et al. ${ }^{34}$ reported that the elderly persons demonstrated an earlier onset of dream periods, as well as more frequent and abrupt awakenings episodes. They looked at nocturnal delirium as a transitional state from dreaming to wakefulness, and abrupt intrusion of dreams into a waking state. Evans ${ }^{13}$ by reviewing the medical charts of a group of institutionalized elderly persons who were suffering from sundowning, has shown a significant relationship between sundowning and disturbances in circadian rhythms. Although the exact time, precise relationship between sundowning symptoms and late afternoon, or sunset hours are not determined yet, there is numerous evidence in the medical literature of the existence of a circadian rhythm for disrupted behaviors in many patients with $\mathrm{AD}$ that peaks in intensity late in the day. ${ }^{8,13,35}$ Satlin et al. ${ }^{20}$ reported that patients with severe $\mathrm{AD}$ have a greater total daily motor activity during night time, as well as less strictly circadian rhythm for motor activity, compared to healthy elderly persons. Another companion study by the same group of researchers has revealed the opposite findings that subjects with severe dementia had less diurnal motor activity and a higher intensity of nocturnal activity, compared to control group. The study conducted by Evans ${ }^{13}$ was consistent with above findings about the relationships between circadian rhythm disturbances and severity of cognitive and behavioral deterioration in demented subjects.

The central components of the physiological basis of the biological circadian rhythm include the suprachiasmatic nucleus (SCN) and melatonin. ${ }^{36}$ The SCN located in hypothalamus plays an important role in circadian rhythm regulation during awake state by producing an alerting signal; during sleep time SCN produces a sleep-inducing signal. ${ }^{37}$ In humans, the circadian rhythm is responsible for sleep-wake cycling. ${ }^{4}$ The SCN acts as the major circadian pacemaker of the human body and influences several physiological functions including the core body temperature, heart rate, and hormone secretion. ${ }^{38}$ Disruption of the circadian rhythms due to deterioration of the SCN observed in patients with $\mathrm{AD}$ may contribute to the development of sundowning syndrome..$^{10,36}$ The possible cause of the SCN deterioration is due to senile plaque formation that increases with age. ${ }^{10}$ These pathological changes may theoretically explain disturbed sleep, agitation, confusion, and other symptoms of sundowning. It is suggested that the volume of SCN, as well as its cell number decreases in persons between the ages of 80 and 100 years. Patients with dementia of the Alzheimer's type have more prominent abnormalities in SCN. ${ }^{36}$ Some researchers have found evidence of deterioration in the SCN at autopsy in patients with $\mathrm{AD} .^{36,39}$ Huitron-Resendiz et al. ${ }^{40}$ demonstrated evidence for a relationship between $\mathrm{AD}$ pathology and circadian rhythm disturbance that has been revealed by studies in transgenic AD mouse models. According to this investigation, aged platelet-derived beta-amyloid precursor protein (PDAPP) transgenic mice exhibited marked sleep deficits in REM and non-REM sleep, as well as deficits in circadian distribution of sleep-wake states. ${ }^{40}$ Data from other studies suggests a possible casual similarity to human sundowning behavior as they reported that the APP23 transgenic mouse model of AD has shown increased motor activation during the second half of the active phase, specifically at ages 6 months and 12 months. ${ }^{41,42}$ Another important component of circadian rhythm regulation is melatonin, a hormone produced by the pineal gland in darkness, and during sleep. ${ }^{40}$ Liu et al. ${ }^{43}$ demonstrated that melatonin level has found to be decreased in the postmortem cerebrospinal fluid levels of patients with AD. This decrease causes deregulation in circadian rhythm and lessens the neuroprotective effect on the SCN. ${ }^{4}$ Natural production of melatonin appears to decrease with aging, which could alter arteriolar wall in elderly persons. ${ }^{45}$ This explains the rationale for use of melatonin in $\mathrm{AD}^{40,46-48}$

\section{Sleep disorders}

According to epidemiological studies, disturbances in duration and quality of sleep increase with aging, and occur in approximately $38 \%$ of persons over 65 -year-old. ${ }^{49,50} 36 \%$ experience difficulties in sleep initiation and $29 \%$ suffer from difficulties in sleep maintenance. ${ }^{50}$ Hess 3 reported that almost half the patients with dementia experience clinically relevant sleep-wake disturbances. Jelicic et al..$^{51}$ demonstrated that subjective sleep disturbances in later life may potentially predict cognitive decline, and negatively correlate with cognitive performance. Bliwise et al..$^{30}$ suggested that disturbances 
in night sleep correlate with severity of dementia. Based on literature, $34-43 \%$ of the patients with $\mathrm{AD}$ suffer from various sleep disturbances. ${ }^{52,53}$ Sleep disturbances in $\mathrm{AD}$, including disrupted chronobiology, sleep disordered breathing, and increased daytime napping, are suggested to be multifactorial. ${ }^{54}$ Although the contribution of sleep disturbances in development of late afternoon or early evening behavioral disruptions in dementia has not been established, there are some evidence about possible relationship between them. According to Bliwise and associates, ${ }^{54,55}$ increased incidence of sleep disorders in patients with $\mathrm{AD}$ may explain nighttime worsening of behavior. REM-sleep disturbances, along with sleep apnea and dysregulation of SCN, are among suggested hypotheses for a possible physiological explanation of sundowning syndrome. ${ }^{56}$ According to this hypothesis, neuronal degeneration of cholinergic nucleus basalis of Meynert (NBM) neurons which modulate the activity of SCN and the induction of non-REM sleep, causes rest-activity cycle disturbances, and promotes sundowning in patients with $\mathrm{AD} .^{54}$ It was reported that patients with dementia have various sleep architecture changes, including an increase in stage I and II sleep, a decrease in stage III and stage IV, decreased consolidation of non-REM sleep, lower sleep efficiency, an increased sleep fragmentation and episodes of awakenings, nocturnal wandering, an increase in daytime napping, as well as higher incidence of disruptive nocturnal behavior. ${ }^{47-49}$ Martin et al. ${ }^{57}$ reported that $42 \%$ of demented nursing home residents suffer from syndrome of sleep apnea. Restless leg syndrome (RLS) and periodic leg movement syndrome (PLMS) are underdiagnosed in elderly demented patients due to inability to describe their symptoms. Patients taking selective serotonin reuptake inhibitor, antipsychotic, and other dopamine depleting medications may potentially develop PLMS as a side effect. ${ }^{58}$ Although there is increased incidence of various sleep disturbances in demented patients, the relationship between sundowing and sleep abnormalities has not been studied to date. Sleep studies should be done to diagnose RLS and PLMS in demented patients with increased daytime sleepiness, and hyperkinetic parasomnias (REM sleep behavior disorder) which may potentially induce, imitate, or complicate sundown syndrome. ${ }^{2}$ Vitiello et al. ${ }^{55}$ reported that initial stages of $\mathrm{AD}$ are characterized by decreased time in stage 3 and 4 non-REM sleep, as well as increased nighttime wakefulness. There is a tendency towards progressive REM sleep loss in more advanced stages of the disease..$^{55}$ Sleep disruption is not pathognomonic to $\mathrm{AD}$, and several studies demonstrated significant sleep disturbances in other types of dementia. In Parkinson's disease and Lewy body dementia sleep disruptions may be even more prominent than in $\mathrm{AD} .^{30,55,57,58}$ Harper et al. ${ }^{32}$ reported that patients with frontotemporal dementia and dementia related to subcortical infarcts, experience less disruption of nighttime sleep than in AD. Hess ${ }^{3}$ has found that in Parkinson's disease, vascular dementia, Korsakoff syndrome, and depression the deterioration of sleep architecture may be prominent, whereas patients with $\mathrm{AD}$ experienced marked hypersomnolence or insomnia mostly in advanced stages of the disease. Other theories suggest that sleep fragmentation is important etiologic factor in sundowning. Bliwise et al. ${ }^{56}$ found that awakenings after sunset time, spontaneous or related to nursing care, induced agitated behavior more frequently in demented nursing home residents.

\section{Maladaptive response to environmental factors}

Cohen-Mansfield et al..$^{58}$ studied the temporal pattern of agitation and fatigue in nursing home residents with dementia. According to this study, only a minority of agitated nursing home residents, especially those with higher baseline level of agitation, showed increased intensity of agitation after 4:00 PM. This finding was not in agreement with widely accepted notion about temporal relation between sunset period and peak in behavioral disruptions including agitation. Patient's confusion, as a manifestation of sundowning, may be a result of the chronic fatigue and disturbed sleep-wake cycle. ${ }^{60}$ Afternoon fatigue, caregiver fatigue, and overstimulation in the environment, as well as shifts change around 3:00 PM when there is more noise and general chaos, all are contributing factors to sundowning. ${ }^{61,62}$ High level of activity in the morning hours and during the day may cause afternoon or evening fatigue, and then lead to increased irritability and agitation in demented patients. ${ }^{63}$

Rindlisbacher and Hopkins ${ }^{5}$ measured agitation in demented Alzheimer's patients in terms of motor activity. Analyses showed that some subjects in this study demonstrated increased afternoon activity, but these subjects did not correspond to nursing-assigned groups of 'sundowners' and 'nonsundowners'. Movement correlates of "sundowning" were seen in patients with $\mathrm{AD}$ presumably in the mid-stages of the dementia, and less so in patients with more advanced stages of the disease. ${ }^{5}$ Cohen-Mansfield et al. ${ }^{11}$ assumed that screaming at night may occur in dementia patients as a response to social isolation. Another possible environmental contributor to sundowning is the lower staff-patient ratio in institutions, or lessened availability of home caregivers at that time of day. It decreases the intensity of structured stimulation for patients, increases boredom, and consequently leads to agitation, restlessness, and other behavioral disruptions associated behavior disorder. On the other hand, with high prevalence of sundowning (66\% among patients living at home), sundowning behavior in demented patient lead to inadequate, fragmented sleep in caregiver, and increases caregiver stress, which may increase the likelihood of sundowning. ${ }^{26,64,65}$ Not surprisingly, 
caregiver stress and burnout may increase the likelihood of institutionalization for the patient. ${ }^{64,65}$ Staff/patient conflicts may arise from lack of communication, splitting staff as a result of the demented patient's specific pathology, or frustration and distress due to decreased physical independence. ${ }^{22}$

\section{Temporal changes in body temperature}

According to two different studies conducted by Volicer ${ }^{4}$ and Satlin, ${ }^{20} \mathrm{AD}$ causes disturbances of circadian rhythms and normal daily cycle of changes in body temperature, and sundown syndrome appears to be related to phase delay of body temperature, the changes that normally occur in the evening. Also, the patients with $\mathrm{AD}$ had less intense motor activity during the day, a higher percentage of activities during the night, lower interdaily stability of motor activity, and a later activity acrophase (time of peak) than did the healthy subjects. Besides that, subjects in this study had a higher mesor (fitted mean) temperature, higher amplitude of the fitted cosine temperature curve, as well as later temperature acrophase than did the healthy individuals. It was established that the severity of sundowning was associated with later acrophase of temperature, less correlation of circadian temperature rhythm within a 24-hour cycle, and also lower amplitude of temperature curve. ${ }^{4}$ This study revealed also that "sundowning" patients have prone to more chaotic temperature rhythm that had minimal relationship to the motor activity recorded. Satlin et al..$^{20}$ found that both, motor activity and body temperature rhythms had later acrophases (time of peak values). Lee et al. ${ }^{66}$ examined the difference in 24-hour rhythms of sleepwake cycle and temperature between $\mathrm{AD}$ patients and elderly subjects as a control group. They demonstrated that the mean acrophase (time of peak values) and amplitudes of the two rhythms in the $\mathrm{AD}$ group were not significantly different from those in the control group. However, the mean phase difference between the two rhythms was significantly lower in the group of patients with $\mathrm{AD}$ than in the control group. ${ }^{66}$

\section{Medications as a contributing factor}

Numerous geriatricians share opinion that sundowning may be a side effect or the "wearing-off" effect of various medications. Several drugs may induce restlessness, akathisia, or more serious movement disorders by causing extrapyramidal symptoms (antidepressants, antipsychotics). Dyskinesias may be secondary to on-off phenomena of anti-Parkinsonian drugs. Some medications may worsen cognition (e.g., through anticholinergic side effects). ${ }^{63}$ It is well-known fact that virtually, any pharmacological agent, and combination of different medications may induce cognitive, affective, and behavioral changes in patients with dementia. Moreover, medications that are used to treat above mentioned changes may worsen pre- viously existing pathology. Hypnotics, benzodiazepines, and low-potency antipsychotics are among conventional therapy that used to manage evening agitation and behavioral disruptions associated with sundowning. Side-effects of such medications, including akathisia, tardive dyskinesia, muscle rigidity, anticholinergic toxicity (tachycardia, constipation, and confusion), orthostatic hypotension, and others may further contribute to development of sundowning in demented patients. Widely used benzodiazepines and other hypnotics to control nocturnal agitation, are considered to be a poor drugs of choice for elderly patients who often have several comorbidities. They tend to create drug tolerance, dependence, withdrawal, and even significantly increase the risk of respiratory and central nervous system depression. These drugs may cause paradoxical agitation, increase disinhibition and confusion in elderly patients with preexisting agitation who have sundowning syndrome. $^{22}$

\section{Medical and psychiatric conditions as a contributing factor}

A vast variety of medical factors can contribute to temporally associated agitation. For example, some diseases in which pain is intense may initiate or worsen cognitive, affective, or behavioral disturbances in the late afternoon. Bachman et al. ${ }^{63}$ reported that agitation may be a manifestation of the response to temporal variation in pain. Mood variability in some demented patients may have predictable pattern, and in major depression worsening of mood in the evening hours (which may characterize atypical pattern of major depression), might possibly explain some cases of sundowning. ${ }^{63}$ It can be hypothesized that agitation and changes in activity in demented patients with depression may be manifested as sundowning; taking into consideration difficulties in eliciting other symptoms of depression in cognitively impaired individuals. ${ }^{63}$ Some researchers theorize that hunger, changes in blood glucose levels after eating in patients with diabetes, or a drop in blood pressure after a meal (which temporarily deprives brain from oxygen), may bring on agitation and confusion in susceptible ${\text { individuals. }{ }^{67}}^{6}$

\section{Diagnosis}

Diagnosis of sundown syndrome is purely clinical, and characterized by wide variety of cognitive, affective, and behavioral abnormalities which all have temporal pattern with symptom emergence or worsening in late afternoon, at evening, or at night. There has not been found any data on specific laboratory findings, imaging studies, or electrophysiologic studies in sundown syndrome in researched medical literature. It is not intent of this literature review to provide a comprehensive search specifically on diagnosis of sundowning syndrome. 


\section{Differential diagnosis}

A major difference between sundowning and delirium will be that delirium tends to be relatively acute in onset, relatively brief (a matter of hours or days), and fluctuating in the course of the day. Although fluctuating, delirium will not share the pattern of fluctuation characterized for sundowning, when prominent onset and exacerbation of cognitive and behavioral disruption brought on by late afternoon, early evening, or night hours. Therefore, the cardinal differentiation between delirium and sundowning is supposed to be made in terms of temporal characteristics, and primarily, on the basis of the onset and termination. It is not known to date, whether the pathophysiological mechanisms involved with the demented patient in the onset of sundowning are the identical or at least similar to delirium. ${ }^{68,69}$ In majority of cases, patients already have some degree of medical or cognitive compromise prior to the development of sundowning. Moreover, in demented patients there is always a possibility of delirium due to various medical reasons, and there is a great challenge for clinician to differentiate delirium due to medical condition from sundowning in cognitively compromised patients. It was suggested that delirium may be a pre-condition for nocturnal delirium. In respect to differentiation between delirium, and sundowning, Duckett ${ }^{22}$ stated that dementia may in fact be a necessary but not a sufficient condition: not all demented patients sundown, but virtually all sundowning patients are demented, as well as delirious at the time of their sundowning episode.

\section{Treatment}

Both non-pharmacologic and pharmacologic approaches have been considered in the treatment of patients with sundowning. According to the reviewed literature, among medical factors which may contribute to sundowning in the elderly individuals with dementia are: chronic pain syndrome due to arthritis and malignancy, organ systemic disorders (including congestive heart failure, ischemic heart disease, asthma, chronic obstructive pulmonary disease, gastroesophageal reflux, incontinence, benign prostatic hypertrophy), psychiatric conditions (including depression, anxiety, psychosis), and effects of various medications. ${ }^{19,63,70}$ In demented patients, physical discomfort and illness may also be expressed as behavioral abnormalities. Individuals with $\mathrm{AD}$ are not able to react to pain or other physical discomfort in standard ways, as well as to relate to their body properly. That is why elderly demented patients often use aggression and other behaviors, such as yelling, screaming and refusing to eat to express pain or other physical symptoms. It was suggested to use "S-M-A-R-T" or "P.I.E.C.E.S." ${ }^{\text {"72 }}$ approaches in management of dementia-related behavioral problems. The former includes Safety, medical work-up, assessment of competency, rest/review of causes of behavioral abnormalities, and trial of medications. The latter includes considering physical problems, Intellectual/cognitive changes, emotional problems, capabilities, environment, social/cultural issues. Considering sundowning symptoms being a part of behavioral and psychological symptoms of dementia, it is reasonable to use the same "S-M-A-R-T" or "P. I.E.C.E.S" approaches in complex treatment of behavioral manifestations of sundown syndrome. Therefore, before considering any specific treatment for sundown syndrome in elderly demented patients, it is reasonable to gather a careful history, perform thorough physical examination, and laboratory investigations in order to evaluate a patient for temporal patterns of agitation and other manifestations of sundowning syndrome, and its possible connection to various medical conditions. According to data from current medical literature, the following interventions have been tried and found to be somewhat effective for the treatment of sundowning in demented patients: bright light therapy, melatonin, acetylcholinesterase inhibitors, antipsychotic medications, and environmental intervention/ behavioral modifications.

\section{Light therapy}

One of the environmental modifications that have been suggested by several researchers for empirical treatment of sundowning syndrome is light therapy. ${ }^{73-82}$

A review of the available ambient light in the patient's room demonstrated that in different portions of the hospital there was a significant difference in available light that was not immediately obvious to the healthy eye. ${ }^{22}$ Increased amount of lighting in the evening hours may considerably assist the elderly patient with neurologically compromised brain in re-orienting. ${ }^{73}$ It was suggested by Duckett ${ }^{22}$ to modify ambient light by matching light readings obtained from the day and evening hours.

It was reported that the placing a full-spectrum fluorescent lamp (between 2,500 and 5,000 lux) about 1 meter from the sundowning patient within his or her visual field for a couple of hours in the morning may change the patient's circadian rhythm, and make demented individual less agitated at confused. It may be achieved by turning light on while the patient is watching television or doing other daily activities. ${ }^{74}$ In one study, the patients suffering from $\mathrm{AD}$, sundown syndrome, and difficulties with sleep maintenance that were treated with bright light, have demonstrated improved sleep quality and less sundowning episodes. ${ }^{75-77}$ In another study, Murphy and Campbell ${ }^{78}$ have found that during the exposure to bright light there was progression in cognitive functioning in elderly individuals. In a 6-week, double-blind, placebo-controlled, crossover trial the effects of bright light therapy combined with melatonin on motor restless behavior in demented patients 
had been evaluated. ${ }^{79}$ This study concluded that bright light therapy (10,000 lux bright light) has a positive effect on motor restlessness in subjects with dementia. A review of the Cochrane meta-analysis related to light therapy for managing sleep, behavior, and mood disturbances in dementia did not demonstrate the effectiveness of specific light therapy ${ }^{80}$ Okawa et al. ${ }^{81}$ reported positive effect of phototherapy on sleepwake disorders in elderly demented patients. Another report demonstrated that treatment with bright light improved agitated behavior in institutionalized elderly patients. ${ }^{82}$

\section{Melatonin}

Several studies suggested that circadian rhythm disruptions in individuals with dementia have been linked to decreased or dysregulated melatonin level and abnormalities in the SCN in this patient population, and possibly related to development of sundowning behavior., ${ }^{40,29-34,83-88}$ These studies served as a rationale for the treatment of circadian rhythm- related behavioral problem such as sundowning with melatonin. A systematic review of literature related to treatment of elderly patients with insomnia (1990-2000) revealed 12 studies with empirical treatment results for melatonin in the elderly. ${ }^{89} \mathrm{Am}$ ong these 12 studies, 6 double-blind controlled trials analyzed results by objective measurements of sleep quality. Decrease in sleep latency was registered in 4 studies. Three doubleblind controlled trials found improvement in such objective characteristics of sleep quality as total sleep time, sleep efficiency, and wake time during sleep) as a result of melatonin treatment, although there was no improvement in subjective sleep quality. Another 6 open-label or retrospective case studies showed a trend toward decreased sundowning and improved sleep quality..$^{90}$ Several recent studies which reflect use of melatonin specifically in patients with dementia, demonstrated that melatonin reduces sundowning behavior, nocturnal activity, decreases sleep latency, and improves quality of sleep. ${ }^{89-91}$ De Jonghe et al. ${ }^{47}$ performed a systematic search of the literature related to melatonin treatment in dementia which was published between 1985 and 2009. Four randomized controlled trials (RCTs), including 243 participants, and five case series including 87 participants have been analyzed. Two of the RCTs demonstrated a remarkable improvement of agitation and other manifestations of sundowning syndrome. Improvement of sundowning behavior was reported in all five case series. Based on this literature review, the effect of melatonin treatment on sleep quality and daytime functioning were inconclusive.$^{47}$ Cohen-Mansfield et al. ${ }^{48}$ in a pilot study investigated the effect of melatonin treatment on improving sleep and reducing sundowning in 11 demented elderly nursing home residents. Results of this study showed a significant decrease in agitated behaviors during the day, as well as marked decrease in daytime sleepiness in subjects after treatment with melatonin. There was a slight decrease in sleep latency in the evening hours. The night-time sleep ratings were not remarkably changed in these patients. ${ }^{48}$ Although Haffmans et al. ${ }^{79}$ demonstrated that bright light therapy (10,000 lux bright light) has a positive effect on motor restlessness in demented patients, combination of melatonin with bright light does not result in any improvement of motor restless behavior in this patient population. Authors of this study hypothesized that combination of two zeitgebers (bright light and melatonin) may be "too much" in regulation of disruptive behavior. Also, it was possible that melatonin has very little effect on regulation of abnormal behavior in demented subjects. In accordance to this result, Rao et al..$^{92}$ found that treatment with bright light modifies the circadian melatonin profile of depressed patients and healthy controls only minimally. Singer et al..$^{93}$ analyzed effect of melatonin on sleep disturbances in patients with $\mathrm{AD}$ in a double-blind placebo-controlled study of 36 centers with 156 nursing home subjects. He did not find any benefits of melatonin for treatment of insomnia in studied subjects. Therefore, based on this literature review, there is no conclusive date related to effectiveness of melatonin treatment for sundowning in demented patients.

\section{Acetylcholinesterase inhibitors}

Although acetylcholinesterase inhibitors (AChEIs) are the standard of treatment of mild and moderate AD in the United States, there is no clear evidence of their benefit in controlling behavioral symptoms, including sundowning. Data related to effect of different AChEIs on sundowning behavior are limited, and contradictory to date. Ross et al. ${ }^{94}$ and Rogers et al..$^{95}$ suggested that donepezil might worsen nocturnal agitation and other behavioral disruptions in demented patients at night by inducing insomnia or nightmares. Rogers et al. ${ }^{95}$ also demonstrated that $10 \%$ of patients who were treated with donepezil experienced insomnia. Insomnia as a side effect may be less prominent with galantamine and rivastigmine than with donepezil. ${ }^{96,97}$ Nevertheless, no differences have been demonstrated in sleep measures between the galantamine and placebo in the evaluation of subjects using the Pittsburg Sleep Quality Index. ${ }^{96}$ There was recommendation to attenuate adverse effects of donepezil on sleep by slow dose escalation tapering, as well as by switching evening dose to morning dose. ${ }^{98}$ Another study showed that donepezil given once a day in the morning has increased sleep efficiency and shortened sleep latency. ${ }^{99}$ Several reports have described the effect of donepezil and other AChEIs on cognitive function, behavioral abnormalities, and sundowning in dementia with Lewy Bodies. ${ }^{100-102}$ Skjerve et al. ${ }^{100}$ reported an improvement in sundowning symptoms in 71-year-old man with clinically di- 
agnosed dementia with Lewy bodies after treatment with donepezil. The positive results of the treatment included a marked reduction in evening activity and increase in daytime activity, as measured using the activity electronic monitoring technique, along with improved cognition and Parkinsonism. ${ }^{100}$ MacLean et al. ${ }^{102}$ reported decreased dreaming behavior in Lewy body dementia patients treated with rivastigmine. Another open-label trial showed improvement of cognitive functioning and psychosis in patient with Parkinson's disease as a result of treatment with rivastigmine. ${ }^{103}$ Stahl et al. ${ }^{104}$ evaluated results from three randomized double-blind trials of galantamine versus placebo in $\mathrm{AD}$. They revealed no increase in insomnia or other sleep problems and nightmares but no reduction in sleep disturbances. ${ }^{104}$ Recent multiple RCTs demonstrated positive impact of galantamine, ${ }^{105}$ rivastigmine, ${ }^{106-108}$ and donepezil ${ }^{109-111}$ on behavioral and psychological symptoms of dementia, although they did not address specifically effect of above medications on sundowning symptoms. Currently, there is no specific data are available on treatment of sundowning syndrome with N-methyl-d-aspartate (NMDA) receptor antagonist memantine. Most of the studies are addressing common behavioral abnormalities, agitation, aggression, and psychosis in patients with $\mathrm{AD}^{112}$ However, Forchetti ${ }^{113}$ disagrees with using memantine to modify behavior, because the clinical trials did not demonstrate a significant effect on the Neuropsychiatric Inventory, the instrument used to measure changes in behavioral symptoms.

\section{Antipsychotic medications}

Although antipsychotics are probably the most widely used class of medications to manage symptoms of sundowning, there is limited information available in the medical literature on this particular topic. Majority of studies are reflecting use of antipsychotic medications in demented individuals for various behavioral disruptions, including psychosis and agitation, but not specifically for sundowning. ${ }^{114-129}$ Stoope et al. ${ }^{114}$ reported that $>40 \%$ of family practitioners and neuropsychiatrists in Germany considered antipsychotic medications to be the drugs of choice for treatment of sundowning and other sleep disturbances in elderly demented patients. Numerous RCTs are supported the effectiveness of several antipsychotic medications (risperidone, olanzapine, aripiprazole) for the treatment of behavioral symptoms in dementia. ${ }^{119-123}$ Another report reflected the use of quetiapine for behavioral disruptions and psychosis in nursing home residents with $\mathrm{AD} .^{124}$ The Clinical Antipsychotic Trials of Intervention Effectiveness-Alzheimer's Disease demonstrated that atypical antipsychotic use was associated with marked improvement in paranoid ideations, aggression, and anger. ${ }^{127}$ Tariot $^{115}$ reported that antipsychotic medications exhibit modest effects on agitation in patients with severe dementia with only $15-20 \%$ effect size over placebo. He also demonstrated that about one third of patients on antipsychotic medications may experience mild sedation, which may be favorable in sleep facilitation. Another study suggested antipsychotic medications for treatment of various sleep disturbances and maladaptive behaviors at nighttime in severely demented nursing home residents. ${ }^{121}$ It was reported that there was even slight effect of antipsychotic treatment on daytime agitation, and after discontinuation of antipsychotic medications for four weeks, the global behavioral scores remained relatively stable or improved in majority of subjects. ${ }^{116}$ Standbridge ${ }^{128}$ suggested atypical antipsychotics for the treatment of sundowning and confusion in the evening, due to their sedative side effects. Parnetti ${ }^{129}$ demonstrated that atypical antipsychotics at very low dosages can be used to treat delusions, hallucinations, and paranoid ideations. Atypical antipsychotics, comparing to typical antipsychotics, have more favorable side-effect profile. ${ }^{2}$ Nevertheless, its use should be carefully weighed against such life-threatening side effects as pneumonia, stroke, and death. ${ }^{130-132}$ Risperidone, is one of the commonly used agent, has been shown to decrease nocturnal agitation in nursing home residents. ${ }^{118}$ Another study demonstrated reduction of aggressiveness and wandering, as well as increase nighttime sleeping hours in demented patients treated with risperidone. ${ }^{117}$ It was recommended to reassess cognitive and behavioral status of demented patients on antipsychotic medications on a regular basis: within 3 months after treatment initiation (Canadian treatment guidelines), ${ }^{133}$ or at least every 3 to 6 months if they are outpatients. ${ }^{128,129}$ While there are no specific studies related to use of atypical antipsychotics for the treatment of sundowning, they might be considered as effective medications for this purposes, especially because these drugs are better tolerated than typical antipsychotics in the elderly patients. ${ }^{2}$

\section{Environmental interventions/Behavioral modifications}

Results from the studies related to behavioral interventions for management of neurpsychiatric symptoms of dementia are inconsistent. Although it has been difficult to validate effectiveness of specific therapies for sundowning syndrome, several clinical observations has led to the emergence of various recommendations and intervention strategies. Different clinicians agree on these strategies that empirically support their usefulness. ${ }^{62}$ Individually tailored non-pharmacological approaches for management of behavioral disruptions, including sundowning, considered to be the first-line therapy, and should be attempted before pharmacologic interventions. ${ }^{133,134}$ The following management options has been suggested as possible interventions for behavioral abnormalities in dementia, which theoretically might be effective for sundowning as well: 
light therapy, ${ }^{73-82,135}$ music therapy, ${ }^{136}$ aromatherapy, ${ }^{137}$ caregiver education, ${ }^{138}$ multisensory stimulation, ${ }^{139}$ and simulated presence therapy. ${ }^{140}$ Other recommendations include reduction of noisy background, minimizing unnecessary noise (e.g., noise from visitors, loud speakers, banging of dishes, loud staff conversation), offering simple instructions for meals and bathing, adherence to a stable daily routine. ${ }^{2,62,63,141}$ More detailed information about a non-pharmacologic management of behavioral disruptions in $\mathrm{AD}$ can be found in the recently reported findings of the Resources for Advancing Alzheimer's Caregiver's Health (REACH) trial, the largest randomized controlled clinical trial to date, involving 1222 caregiver and care recipients recruited from 6 different sites in the United States. ${ }^{74}$ Several clinicians suggest that involvement of demented patients in structured, planned activities may reduce likelihood of behavioral disruptions, including agitation, especially if these activities specifically scheduled at the times of agitation, or before beginning of behavioral abnormalities. ${ }^{2,62}$ It was recommended to follow sleep hygiene routine, try to keep demented patient mentally occupied during the day, adhere to a structured daily schedule, and provide opportunities for physical exercise. ${ }^{141}$ Meeting physical needs, addressing pain, dyskinesias, constipation, and other physical discomfort is crucial in preventing agitation, confusion, and other behavioral disturbances in demented patients. ${ }^{63}$ Redirection, reassurance, and distraction as clinical tools, can be learned by nursing staff and caregivers, and should be included in treatment plan. ${ }^{63}$ It was strongly recommended for caregivers to monitor television-viewing by demented patients, especially during evening hours. Some frightening or violent events depicted on television, may be very stressful and disturbing for cognitively impaired individuals, as they may believe that these events are actually happening to them in reality. As a result, these patients may express their fears in the form of agitation, confusion, or violence. ${ }^{113}$ Creation of relaxing environment is another useful tool to ease sundown syndrome in demented patients. Listening CD with favorite music, sounds of nature (ocean waves, bird's songs, or mountain stream) might relax and calm patient down. In case of agitation due to hunger, or thirst, just offering a food, snack or something to drink may ease discomfort and reduce behavioral disruption. Talking to the patient with soft, calm voice, doing hand massage, or just holding his hand may reassure patient and diminish anxiety. ${ }^{74}$ Other general recommendations include management of depression, feelings of guilt, sadness, grief, feelings of worthlessness, anxiety and frustration. It may also be provoked by confusion related to cognitive impairment, and induce agitation, sleep disturbances, which all may contribute to emergence or worsening of sundowning. ${ }^{113}$

\section{Prognosis}

There has been very little research data on prognosis of the sundown syndrome. Scarmeas et al. ${ }^{25}$ reported that the presence of sundown syndrome has been associated with more rapid cognitive function deterioration in patients with early stages of $\mathrm{AD}$.

\section{Prevention}

Exploration of potential etiologic factors of sundowning syndrome (environmental, physiological, psychological) in each demented individual, as well as addressing modifiable factors with appropriate interventions, seems to be the best way to prevent clinical symptoms of sundowning. There is limited data in current medical literature on effective methods of prevention of sundowning syndrome in dementia. Nevertheless, it might be hypothesized, that several interventions that have been used to treat sundowning syndrome, may have been considered in prevention of this clinical phenomena. These interventions are as follows: environmental interventions/ behavioral modifications as a first line treatment, ${ }^{133,134}$ including light therapy ${ }^{73-82,135}$ music therapy, ${ }^{136}$ aromatherapy, ${ }^{137}$ caregiver education, ${ }^{138}$ multisensory stimulation, ${ }^{139}$ and simulated presence therapy, ${ }^{140}$ following sleep hygiene routine, adherence to a structured daily schedule, and physical exercise. ${ }^{141}$ There is no clear evidence that prophylactic use of melatonin, AChEIs, or NMDA receptor antagonist is effective in prevention of sundown syndrome development in dementia.

\section{CONCLUSION}

Factors underlying clinical manifestations of sundowning are usually multifaceted, and requiring biopsychosocial approaches to assessment and treatment. Various behavioral disruptions, including sundowning syndrome in $\mathrm{AD}$ and other types of dementia, have become an increasingly important topic of clinical investigations. The emergence or worsening of behavioral disturbances in cognitively impaired individuals has been recognized by clinicians for the last several decades, which prompted researchers to utilize different methods to investigate the circadian rhythm, hormonal, physiological, pharmacological, iatrogenic, psychological, and other possible correlations with sundowning symptoms. Frequently observed behavioral abnormalities in demented patients with exacerbation in the late afternoon, evening, or at night, pose a significant burden and challenge to caregivers, families, and nursing staff. Finding complex etiological relationships between triggering factors and various manifestations of sundowning syndrome may lead to effective management of this clinical phenomenon. 


\section{REFERENCES}

1. Cameron DE. Studies in senile nocturnal delirium. Psychiatr Q 1941;15: 47-53.

2. Kim P, Louis C, Muralee S, Tampi RR. Sundowning syndrome in the older patient. Clin Geriatr 2005;13:32-36.

3. Hess CW. Sleep disorders and dementia. Praxis (Bern 1994) 1997;86: 1343-1349.

4. Volicer L, Harper DG, Manning BC, Goldstein R, Satlin A . Sundowning and circadian rhythms in Alzheimer's disease. Am J Psychiatry 2001; 158:704-711.

5. Rindlisbacher P, Hopkins RW. An investigation of the sundowning syndrome. Int J Geriatr Psychiatry 1992;7:15-23.

6. Prinz PN, Raskind MA. Aging and Sleep Disorders. In: Williams RL, Karacan I, Editors: Sleep Disorders: Diagnosis and Treatment. New York: John Wiley and Sons; 1978.

7. Sadock BJ. Signs and Symptoms in Psychiatry. In: Sadock BJ, Sadock VA, Editors. Kaplan \& Sadock's Comprehensive Textbook of Psychiatry, 7th Edition. Baltimore: Lippincott Williams \& Willkins; 2000.

8. Bliwise DL. What is sundowning? J Am Geriatr Soc 1994;42:10091011.

9. Bliwise DL, Lee KA. Development of an agitated behavior rating scale for discrete temporal observations. J Nurs Meas 1993;1:115-124.

10. Martin J, Marler M, Shochat T, Ancoli-Israel S. Circadian rhythms of agitation in institutionalized patients with Alzheimer's disease. Chronobiol Int 2000;17:405-418.

11. Cohen-Mansfield J, Watson V, Meade W, Gordon M, Leatherman J, Emor C. Does sundowning occur in residents of an Alzheimer's unit? Int J Geriatr Psychiatry 1989;35:101-108.

12. Bliwise DL, Yesavage JA, Tinklenberg JR. Sundowning and rate of decline in mental function in Alzheimer's disease. Dementia 1992;3:335341.

13. Evans LK. Sundown syndrome in institutionalized elderly. J Am Geriatr Soc 1987;35:101-108.

14. Cohen-Mansfield J, Marx MS, Werner P, Freedman L. Temporal patterns of agitated nursing home residents. Int Psychogeriatr 1992;4: 197-206.

15. Burgio LD, Scilley K, Hardin JM, Janosky J, Bonino P, Slater SC, et al. Studying disruptive vocalization and contextual factors in the nursing home: computer-assisted real-time observation. J Gerontol 1994;49: P230-P239.

16. O'Leary PA, Haley WE, Paul PB. Behavioral assessment in Alzheimer's disease: use of a 24-hr log. Psychol Aging 1993;8:139-143.

17. Sloane PD, Mitchell CM, Pressier JS, Phillips C, Commander C, Burker E. Environmental correlates of resident agitation in Alzheimer's disease special care units. J Am Geriatr Soc 1998;46:862-869.

18. Kutner NG, Bliwise DL. Observed Agitation and the Phenomenon of "Sundowning" among SCU Residents. In: Holmes D, Teresi JA, Ory M, Editors. Research and Practice in Alzheimer's Disease. New York: Springer, 2000, p.151-161.

19. Little JT, Satlin A, Sunderland T, Volicer L. Sundown syndrome in severely demented patients with probable Alzheimer's disease. J Geriatr Psychiatry Neurol 1995;8:103-106.

20. Satlin A, Volicer L, Stopa EG, Harper D. Circadian locomotor activity and core-body temperature rhythms in Alzheimer's disease. Neurobiol Aging 1995;16:765-771.

21. Alzheimer's Association. 2006 Statistics about Alzheimer's disease. Available at: http://www.alz.org/About AD/statistics.asp. Accessed November 2, 2006.

22. Duckett S. Managing the sundowning patient. J Rehabil 1993;1:24-28.

23. U.S. Congress, Office of Technology Assessment. Special Care Units for People With Alzheimer's and Other Dementias: Consumer Education, Research, Regulatory, and Reimbursement Issues. Washington, DC: Government Printing Office; 1992.

24. Devanand DP, Brodkington CD, Moody BJ, Brown RP, Mayeux R,
Endicott J, et al. Behavioral syndromes in Alzheimer's disease. Int Psychogeriatr 1992;4(Suppl 2):161-184.

25. Scarmeas N, Brandt J, Blacker D, Albert M, Hadjigeorgiou G, Dubois $\mathrm{B}$, et al. Disruptive behavior as a predictor in Alzheimer disease. Arch Neurol 2007;64:1755-1761.

26. Gallagher-Thompson D, Brooks JO 3rd, Bliwise D, Leader J, Yesavage JA. The relations among caregiver stress, "sundowning" symptoms, and cognitive decline in Alzheimer's disease. J Am Geriatr Soc 1992; 40:807-810.

27. Ancoli-Israel S, Gehrman P, Martin JL, Shochat T, Marler M, CoreyBloom J, et al. Increased light exposure consolidates sleep and strengthens circadian rhythms in severe Alzheimer's disease patients. Behav Sleep Med 2003;1:22-36.

28. Morley JE. Nocturnal agitation: Sleep Disorders and Insomnia in the Elderly. Facts Res Gerontology 1993;7:103-116.

29. Smith G. What is sundowning? Answer to question "Sundowning: late day confusion". Available at: http://www.mayoclinic.com/health/sundowning/HQ01463. Accessed November 17, 2010.

30. Bliwise DL, Watts RL, Watts N, Rye DB, Irbe D, Hughes M. Disruptive nocturnal behavior in Parkinson's disease and Alzheimer's disease. J Geriatr Psychiatry Neurol 1995;8:107-110.

31. Grace JB, Walker MP, McKeith IG. A comparison of sleep profiles in patients with dementia with Lewy bodies and Alzheimer's disease. Int J Geriatr Psychiatry 2000;15:1028-1033.

32. Harper DG, Stopa EG, McKee AC, Satlin A, Harlan PC, Goldstein R, et al. Differential circadian rhythm disturbances in men with Alzheimer's disease and frontotemporal degeneration. Arch Gen Psychiatry 2001;58:353-360.

33. Bliwise DL, Rye DB, Dihenia B, Gurecki P. Greater daytime sleepiness in subcortical stroke relative to Parkinson's disease and Alzheimer's disease. J Geriatr Psychiatry Neurol 2002;15:61-67.

34. Feinberg I, Koreski RL, Schaffner IR. Sleep electroencephalographic and eye-movement patterns in patients with chronic brain syndrome. J Psychiatr Res 1965;39:11-26.

35. Yesavage JA, Friedman L, Ancoli-Israel. Annu Rev Med 2006; 57:499511.

36. Swaab DF, Fliers E, Partiman TS. The suprachiasmatic nucleus of the human brain in relation to sex, age and senile dementia. Brain Res 1985; 342:37-44.

37. Van Gelder RN. Blue light and the circadian clock. Br J Ophthalmol 2004;88:1353.

38. Wu YH, Swaab DF. The human pineal gland and melatonin in aging and Alzheimer's disease. J Pineal Res 2005;38:145-152.

39. Stopa EG, Volicer L, Kuo-Leblanc V, Harper D, Lathi D, Tate B, et al. Pathologic evaluation of the human suprachiasmatic nucleus in severe dementia. J Neuropathol Exp Neurol 1999;58:29-39.

40. Huitrón-Reséndiz S, Sanchez-Alavez M, Gallegos R, Berg G, Crawford E, Giacchino JL, et al. Age-independent and age-related deficits in visuospatial learning, sleep-wake states, thermoregulation and motor activity in PDAPP mice. Brain Res 2002;928:126-137.

41. Huitrón-Reséndiz S, Sanchez-Alavez M, Criado JR. Sleep-wake states in transgenic mouse models overexpressing the human beta-amyloid precursor protein. Am J Alzheimers Dis Other Demen 2005;20:87-90.

42. Vloeberghs E, Van Dam D, Engelborghs S, Nagels G, Staufenbiel M, De Deyn PP. Altered circadian locomotor activity in APP23 mice: a model for BPSD disturbances. Eur J Neurosci 2004;20:2757-2766.

43. Liu RY, Zhou JN, van Heerikhuize J, Hofman MA, Swaab DF. Decreased melatonin levels in postmortem cerebrospinal fluid in relation to aging, Alzheimer's disease, and apolipoprotein E-epsilon 4/4 genotype. J Clin Endocrinol Metab 1999;84:323-327.

44. Reiter RJ, Tan DX, Manchester LC, El-Sawi MR. Melatonin reduces oxidant damage and promotes mitochondrial respiration: Implications for aging. Ann N Y Acad Sci 2002;959:238-250.

45. Wu YH, Feenstra MG, Zhou JN, Liu RY, Torano JS, Van Kan HJ, et al. Molecular changes underlying reduced pineal melatonin levels in Al- 
zheimer's disease: alterations in preclinical and clinical stages. J Clin Endocrinol Metab 2003;88:5898-5906.

46. Cardinali DP, Brusco LI, Liberczuk C, Furio AM. The use of melatonin in Alzheimer's disease. Neuro Endocrinol Lett 2002;23(Suppl 1):20-23.

47. de Jonghe A, Korevaar JC, van Munster BC, de Rooij SE. Effectiveness of melatonin treatment on circadian rhythm disturbances in dementia. Are there implications for delirium? A systematic review. Int J Geriatr Psychiatry 2010;25:1201-1208.

48. Cohen-Mansfield J, Garfinkel D, Lipson S. Melatonin for treatment of sundowning in elderly persons with dementia-a preliminary study. Arch Gerontol Geriatr 2000;31:65-76.

49. Klaffke S, Staedt J. Sundowning and circadian rhythm disorders in dementia. Acta Neurol Belg 2006;106:168-175.

50. Foley DJ, Monjan AA, Brown SL, Simonsick EM, Wallace RB, Blazer DG. Sleep complaints among elderly persons: an epidemiologic study of three communities. Sleep 1995;18:425-432.

51. Jelicic M, Bosma H, Ponds RW, van Boxtel MP, Houx PJ, Jolles J. Subjective sleep problems in later life as predictors of cognitive decline. Report from the Maastricht Ageing Study (MAAS). Int J Geriatr Psychiatry 2002;17:73-77.

52. Tractenberg RE, Singer CM, Cummings JL, Thal LJ. The sleep disorders inventory: an instrument for studies of sleep disturbance in persons with Alzheimer's disease. J Sleep Res 2003;12:331-337.

53. Cacabelos R, Rodriguez B, Carrera C, Caamaño J, Beyer K, Lao JI, et al. APOE-related frequency of cognitive and noncognitive symptoms in dementia. Methods Find Exp Clin Pharmacol 1996;18:693-706.

54. Bliwise DL. Sleep disorders in Alzheimer's disease and other dementias. Clin Cornerstone 2004;6(Suppl 1A):S16-S28.

55. Vitiello MV, Prinz PN. Sleep/Wake Patterns and Sleep Disorders in Alzheimer's Disease. In: Thorpy MJ, Editor. Handbook of Sleep Disorders. New York: Marcel Dekker, 1990, p.703-718.

56. Bliwise DL, Carroll JS, Lee KA, Nekich JC, Dement WC. Sleep and "sundowning" in nursing home patients with dementia. Psychiatry Res 1993;48:277-292.

57. Martin JL, Mory AK, Alessi CA. Nighttime oxygen desaturation and symptoms of sleep- disordered breathing in long-stay nursing home residents. J Gerontol A Biol Sci Med Sci 2005;60:104-108.

58. Horiguchi J, Yamashita H, Mizuno S, Kuramoto Y, Kagaya A, Yamawaki S, et al. Nocturnal eating/drinking syndrome and neurolepticinduced restless legs syndrome. Int Clin Psychopharmacol 1999;14: 33-36.

59. Cohen-Mansfield J, Werner P, Freedman L. Sleep and agitation in agitated nursing home residents: an observational study. Sleep 1995;18: 674-80.

60. Kral VA. Confusional States/Descriptions and Management. In: Howells JG, Editor. Modern Perspectives in the Psychiatry of Old Age. New York: Brunner \& Mazel; 1975.

61. Jacobson S, Pies R, Katz I. Clinical Manual of Geriatric Psychopharmacology. Washington, DC: American Psychiatric Publishing, Inc., 2007, p.580-586.

62. Mace N, Rabins P. The 36 Hour Day. New York: Grand Central Publishing, 2006, p.234-235.

63. Bachman D, Rabins P. "Sundowning" and other temporary associated agitation states in dementia patients. Annu Rev Med 2006;57:499-511.

64. Pollak CP, Perlick D, Linsner JP, Wenston J, Hsieh F. Sleep problems in the community elderly as predictors of death and nursing home placement. J Community Health 1990;15:123-135.

65. Pollak CP, Perlick D. Sleep problems and institutionalization of the elderly. J Geriatr Psychiatry Neurol 1991;4:204-210.

66. Lee JH, Friedland R, Whitehouse PJ, Woo JI. Twenty-four-hour rhythms of sleep-wake cycle and temperature in Alzheimer's disease. J Neuropsychiatry Clin Neurosci 2004;16:192-198.

67. Margiotta A, Bianchetti A, Ranieri P, Trabucchi M. Clinical characteristics and risk factors of delirium in demented and not demented elderly medical inpatients. J Nutr Health Aging 2006;10:535-539.
68. Lipowski Z. Delirium: Acute brain failure in man. Springfield, IL: Charles C Thomas; 1980.

69. Lipowski ZJ. Transient cognitive disorders (delirium, acute confusional states) in the elderly. Am J Psychiatry 1983;140:1426-1436.

70. Exum ME, Phelps BJ, Nabers LE, Osborne JG. Sundown syndrome: is it reflected in the use of PRN medications for nursing home residents? Gerontologist 1993;33:756-761.

71. Rabheru K. Take a S-M-A-R-T Approach: Unpredictable course of dementia symptoms can be managed. Can Fam Physician 2003;49:389.

72. P.I.E.C.E.S. Putting the P.I.E.C.E.S. together. Tillsonburg (ON ): P.I.E.C.E.S. Available at: http://www.piecescanada.com/index.htm. Accessed May 20; 2009.

73. Campbell SS, Kripke DF, Gillin JC, Hrubovcak JC. Exposure to light in healthy elderly subjects and Alzheimer's patients. Physiol Behav 1988; 42:141-144.

74. McGonigal-Kenney ML, Schutte D. Non-pharmacologic Management of Agitated Behaviors in Persons with Alzheimer Disease and Other Chronic Dementing Illnesses. Iowa City, IA: University of Iowa Gerontological Nursing Interventions Research Center, Research Dissemination Core, National Guideline Clearinghouse; 2004.

75. Satlin A, Volicer L, Ross V, Herz L, Campell S. Bright light treatment of behavioral and sleep disturbances in patients with Alzheimer's disease. Am J Psychiatry 1992;149:1028-1032.

76. Mishima K, Okawa M, Hishikawa Y, Hozumi S, Hori H, Takahashi K. Morning bright light therapy for sleep and behavior disorders in elderly patients with dementia. Acta Psychiatr Scand 1994;89:1-7.

77. Van Someren EJ, Hagebeuk EE, Lijzenga C, Scheltens P, de Rooij SE, Jonker C, et al. Circadian rest-activity rhythm disturbances in Alzheimer's disease. Biol Psychiatry 1996;40:259-270.

78. Murphy PJ, Campbell SS. Enhanced performance in elderly subjects following bright light treatment of sleep maintenance insomnia. J Sleep Res 1996;5:165-172.

79. Haffmans PM, Sival RC, Lucius SA, Cats Q, van Gelder L. Bright light therapy and melatonin in motor restless behavior in dementia: a placebo-controlled study. Int J Geriatr Psychiatry 2001;16:106-110.

80. Forbes D, Morgan DG, Bangma J, Peacock S, Pelletier N, Adamson J. Light therapy for managing sleep, behaviour, and mood disturbances in dementia. In The Cochrane Library, 2005. Issue 2. Oxford Update Software. Available at: http://cochrane.bireme.br/cochrane/show.php. Accessed 5/12/05.

81. Okawa M, Hishikawa Y, Hozumi S, Hori H. Sleep-wake disorder and phototherapy in elderly patients with dementia. Biol Psychiatry 1994;1: 837-840.

82. Lovell BB, Ancoli-Israel S, Gevirtz R. Effect of bright light treatment on agitated behavior in institutionalized elderly subjects. Psychiatry Res 1995;57:7-12.

83. Uchida K, Okamoto N, Ohara K, Moita Y. Daily rhythm of serum melatonin in patients with dementia of the degenerative type. Brain Res 1996;717:154-159.

84. Dori D, Casale G, Solerte SB, Fioravanti M, Migliorati G, Cuzzoni G, et al. Chrono-neuroendocrinological aspects of physiological aging and senile dementia. Chronobiologia 1994;21:121-126.

85. Mishima K, Tozawa T, Satoh K, Matsumoto Y, Hishikawa Y, Okawa M. Melatonin secretion rhythm disorders in patients with senile dementia and disturbed sleep-waking. Biol Psychiatry 1999;45:417-421.

86. Balan S, Leibovitz A, Zila SO, Ruth M, Chana W, Yassica B, et al. The relation between the clinical subtypes of delirium and the urinary level of 6-SMT. J Neuropsychiatry Clin Neurosci 2003;15:363-366.

87. Shigeta H, Yasui A, Nimura Y, Machida N, Kageyama M, Miura M, et al. Postoperative delirium and melatonin levels in elderly patients. Am J Surg 2001;182:449-454.

88. Ohashi Y, Okamoto N, Uchida K, Iyo M, Mori N, Morita Y. Daily rhythm of serum melatonin levels and effect of light exposure in patients with dementia of the Alzheimer's type. Biol Psychiatry 1999; 45:1646-1652. 
89. Olde Rikkert MG, Rigaud AS. Melatonin in elderly patients with insomnia. A systematic review. Z Gerontol Geriatr 2001;34:491-497.

90. Monti JM, Cardinali DP. A critical assessment of the melatonin effect on sleep in humans. Biol Signals Recept 2000;9:328-339.

91. Asayama K, Yamadera H, Ito T, Suzuki H, Kudo Y, Endo S. Double blind study of melatonin effects on the sleep-wake rhythm, cognitive and non-cognitive functions in Alzheimer type dementia. J Nippon Med Sch 2003;70:334-341.

92. Rao ML, Müller-Oerlinghausen B, Mackert A, Stieglitz RD, Strebel B, Volz HP. The influence of phototherapy on serotonin and melatonin in non-seasonal depression. Pharmacopsychiatry 1990;23:155-158.

93. Singer C, Tractenberg RE, Kaye J, Schafer K, Gamst A, Grundman M, et al. A multicenter, placebo-controlled trial of melatonin for sleep disturbance in Alzheimer's disease. Sleep 2003;26:893-901.

94. Ross JS, Shua-Haim JR. Aricept-induced nightmares in Alzheimer's disease: 2 case reports. J Am Geriatr Soc 1998;46:119-120.

95. Rogers SL, Doody RS, Mohs RC, Friedhoff LT. Donepezil improves cognition and global function in Alzheimer's disease: a 15 week, double-blind, placebo-controlled study. Donepezil Study Group. Arch Intern Med 1998;158:1021-1031.

96. Markowitz JS, Gutterman EM, Lilienfeld S, Papadopoulos G. Sleeprelated outcomes in persons with mild to moderate Alzheimer disease in a placebo-controlled trial of galantamine. Sleep 2003;26:602-606.

97. McKeith I, Del Ser T, Spano P, Emre M, Wesnes K, Anand R, et al. Efficacy of rivastigmine in dementia with Lewy bodies: a randomised, double-blinded, placebo-controlled international study. Lancet 2000; 356:2031-2036

98. Jackson S, Ham RJ, Wilkinson D. The safety and tolerability of donepezil in patients with Alzheimer's disease. Br J Clin Pharmacol 2004; 58(Suppl 1):1-8.

99. Mizuno S, Kameda A, Inagaki T, Horiguchi J. Effects of donepezil on Alzheimer's disease: the relationship between cognitive function and rapid eye movement sleep. Psychiatry Clin Neurosci 2004;58:660-665.

100. Skjerve A, Nygaard HA. Improvement in sundowning in dementia with Lewy bodies after treatment with donepezil. Int J Geriatr Psychiatry 2000;15:1147-1151.

101. Simard M, van Reekum R. The acetylcholinesterase inhibitors for treatment of cognitive and behavioral symptoms in dementia with Lewy bodies. J Neuropsychiatry Clin Neurosci 2004;16:409-425.

102. MacLean LE, Collins CC, Byrne EJ. Dementia with Lewy bodies treated with rivastigmine: effects on cognition, neuropsychiatric symptoms, and sleep. Int Psychogeriatr 2001;13:277-288.

103. Reading PJ, Luce AK, McKeith IG. Rivastigmine in the treatment of parkinsonian psychosis and cognitive impairment: preliminary findings from an open label trial. Mov Disord 2001;16:1171-1174.

104. Stahl SM, Markowitz JS, Papadopoulos G, Sadik K. Examination of nighttime sleep-related problems during double-blind, placebo-controlled trials of galantamine in patients with Alzheimer's disease. Curr Med Res Opin 2004;20:517-524.

105. Herrmann N, Rabheru K, Wang J, Binder C. Galantamine treatment of problematic behavior in Alzheimer disease: post-hoc analysis of pooled data from three large trials. Am J Geriatr Psychiatry 2005;13: 527-534.

106. Figiel G, Sadowsky C. A systematic review of the effectiveness of rivastigmine for the treatment of behavioral disturbances in dementia and other neurological disorders. Curr Med Res Opin 2008;24:157-166.

107. Cummings JL, Koumaras B, Chen M, Mirski D; Rivastigmine Nursing Home Study Team. Effects of rivastigmine treatment on the neuropsychiatric and behavioral disturbances of nursing home residents with moderate to severe probable Alzheimer's disease: a 26-week, multicenter, open-label study. Am J Geriatr Pharmacother 2005;3: 137-148.

108. Gauthier S, Juby A, Rehel B, Schecter R. EXACT: rivastigmine improves the high prevalence of attention deficits and mood and behaviour symptoms in Alzheimer's disease. Int J Clin Pract 2007;61:886-
895.

109. Cummings JL, McRae T, Zhang R; Donepezil-Sertraline Study Group. Effects of donepezil on neuropsychiatric symptoms in patients with dementia and severe behavioral disorders. Am J Geriatr Psychiatry 2006;14:605-612.

110. Barak Y, Bonder E, Zemishlani H, Mirecki I, Aizenberg D. Donepezil for the treatment of behavioral disturbances in Alzheimer's disease: a 6-month open trial. Arch Gerontol Geriatr 2001;33:237-241.

111. Paleacu D, Mazeh D, Mirecki I, Even M, Barak Y. Donepezil for the treatment of behavioral symptoms in patients with Alzheimer's disease. Clin Neuropharmacol 2002;25:313-317.

112. Wilcock GK, Ballard CG, Cooper JA, Loft H. Memantine for agitation/aggression and psychosis in moderately severe to severe Alzheimer's disease: a pooled analysis of 3 studies. J Clin Psychiatry 2008;69: 341-348.

113. Forchetti C. Topics in Geriatrics: Part 2: Update on managing problem behaviors in Alzheimer's disease. Available at: http://mediwire.skyscape.com/main/Default.aspx?P=Content\&ArticleID=140101. Accessed November 12, 2010.

114. Stoppe G, Sandholzer H, Staedt J, Winter S, Kiefer J, Rüther E. Sleep disturbances in the demented elderly: treatment in ambulatory care. Sleep 1995; 18:844-848.

115. Tariot PN. Pharmacological Treatment of Severe Dementia. In: Iqbal K, Winblad B, Editors. Alzheimer's Disease and Related Disorders Research. Bucharest, Romania: Ana Asian Int Acad Aging, 2003, p.653661.

116. Ruths S, Straand J, Nygaard HA, Bjorvatn B, Pallesen S. Effect of antipsychotic withdrawal on behavior and sleep/wake activity in nursing home residents with dementia: a randomized placebo-controlled, double-blinded study. The Bergen District Nursing Home Study. J Am Geriatr Soc 2004;52:1737-1743.

117. Meguro K, Meguro M, Tanaka Y, Akanuma K, Yamaguchi K, Itoh M. Risperidone is effective for wandering and disturbed sleep/wake patterns in Alzheimer's disease. J Geriatr Psychiatry Neurol 2004;17:61-67.

118. Falsetti AE. Risperidone for control of agitation in dementia patients. Am J Health Syst Pharm 2000;57:862-870.

119. Suh GH, Son HG, Ju YS, Jcho KH, Yeon BK, Shin YM, et al. A randomized, double-blind, crossover comparison of risperidone and haloperidol in Korean dementia patients with behavioral disturbances. Am J Geriatr Psychiatry 2004:12:509-516.

120. Katz I, de Deyn PP, Mintzer J, Greenspan A, Zhu Y, Brodaty H. The efficacy and safety of risperidone in the treatment of psychosis in Alzheimer's disease and mixed dementia: a meta-analysis of 4 placebocontrolled clinical trials. Int J Geriatr Psychiatry 2007;22:475-484.

121. Street JS, Clark WS, Gannon KS, Cummings JL, Bymaster FP, Tamura $\mathrm{RN}$, et al. Olanzapine treatment of psychotic and behavioral symptoms in patients with Alzheimer disease in nursing care facilities: a double-blind, randomized, plaacebo-controlled trial. The HGEU Study Group. Arch Gen Psychiatry 2000;57:968-976.

122. Mintzer JE, Tune LE, Breder CD, Swanink R, Marcus RN, McQuade $\mathrm{RD}$, et al. Aripiprazole for the treatment of psychoses in institutionalized patients with Alzheimer dementia: a multicenter, randomized, double-blind, placebo-controlled assessment of three fixed doses. Am J Geriatr Psychiatry 2007;15:918-931.

123. Katz IR, Jeste DV, Mintzer JE, Clyde C, Napolitano J, Brecher M. Comparison of risperidone and placebo for psychosis and behavioral disturbances associated with dementia: a randomized, double-blind trial. Risperidone Study Group. J Clin Psychiatry 1999;60:107-115.

124. Tariot PN, Schneider L, Katz I, Mintzer J, Street J. Quetiapine in nursing home residents with Alzheimer's dementia and psychosis. Presented at the 15th annual meeting of the American Association for Geriatric Psychiatry. Orlando, FL, February 24-27, 2002.

125. De Deyn P, Jeste DV, Auby P, Carson W, Marcus R, Kujawa M, et al. Aripiprazole in dementia of Alzheimer's type. Presented at the 16th annual meeting of American Association for Geriatric Psychiatry. Hono- 
lulu, HI, March 1-4, 2003.

126. Maixner SM, Mellow AM, Tandon R. The efficacy, safety, and tolerability of antipsychotics in the elderly. J Clin Psychiatry 1999;60(suppl 8):29-41.

127. Sultzer DL, Davis SM, Tariot PN, Dagerman KS, Lebowitz BD, Lyketsos CG, et al. CATIE- AD Study Group. Clinical Symptom responses to atypical antipsychotic medications in Alzheimer's Disease: phase 1 outcomes from the CATIE-AD effectiveness trial. Am J Psychiatry 2008;165:844-854.

128. Standridge JB. Pharmacotherapeutic approaches to the treatment of Alzheimer's disease. Clin Ther 2004;26:615-630.

129. Parnetti L. Therapeutic options in dementia. J Neurol 2000;247:163168.

130. Knol W, van Marum RJ, Jansen PA, Souverein PC, Schobben AF, Egberts AC. Antipsychotic drug use and risk of pneumonia in elderly people. J Am Geriatr Soc 2008;56:661-666.

131. Sacchetti E, Trifiro G, Caputi A, Turrina C, Spina E, Cricelli C, et al. Risk of stroke with typical and atypical anti-psychotics: a retrospective cohort study including unexposed subjects. J Psychopharmacol 2008; 22:39-46.

132. Schneider LS, Dagerman KS, Insel P. Risk of death with atypical antipsychotic drug treatment for dementia: meta-analysis of randomized placebo-controlled trials. JAMA 2005;294:1934-1943.

133. Herrmann N, Gauthier S. Diagnosis and treatment of dementia: 6 . Management of severe Alzheimer disease. CMAJ 2008;179:1279-1287.

134. Salzman C, Jeste DV, Meyer RE, Cohen-Mansfield J, Cummings J,
Grossberg GT, et al. Elderly patients with dementia-related symptoms of severe agitation and aggression: consensus statement on treatment options, clinical trials methodology, and policy. J Clin Psychiatry 2008; 69:889-898.

135. Riemersma-van der Lek RF, Swaab DF, Twisk J, Hol EM, Hoogendijk WJ, Van Someren EJ. Effect of bright light and melatonin on cognitive and noncognitive function in elderly residents of group care facilities: a randomized controlled trial. JAMA 2008;299:2642-2655.

136. Vink AC, Briks JS, Bruinsma MS, Scholten RJ. Music therapy for people with dementia. Cochrane Database Syst Rev 2006;CD003477.

137. Nguen QA, Paton C. The use of aromatherapy to treat behavioural problems in dementia. Int Geriatr Psychiatry 2008;23:337-346.

138. Javadpour A, Ahmadzadeh L, Bahredar MJ. An educative support group for family caregivers: impact on caregivers psychological distress and patient's neuropsychiatry symptoms. Int J Geriatr Psychiatry 2009;24:469-471.

139. Milev RV, Kellar T, McLean M, Mileva V, Luthra V, Thompson S, et al. Multisensory stimulation for elderly with dementia: a 24-week singleblind randomized controlled pilot study. Am J Alzheimers Dis Other Demen 2008;23:372-376.

140. Zetteler J. Effectiveness of simulated presence therapy for individuals with dementia: a systematic review and meta-analysis. Aging Ment Health 2008;12:779-785.

141. Schulz R, Belle SH, Czaja SJ, Gitlin LN, Wisniewski SR, Ory MG, et al. Introduction to the special section on Resources for Enhancing Alzheimer's Caregiver Health (REACH). Psychol Aging 2003;18:357-360. 